\title{
Pancreas transplantation
}

National Diabetes Information Clearinghouse (NDIC)

\section{Definitions}

\section{Pancreas}

Defined by National Diabetes Information Clearinghouse (NDIC)

Diabetes

Defined by National Diabetes Information Clearinghouse (NDIC)

\section{Source}

National Diabetes Information Clearinghouse (U.S.). (2009). The diabetes dictionary. [Bethesda, Md.]: U.S. Dept. of Health and Human Services, National Institutes of Health, National Institute of Diabetes and Digestive and Kidney Diseases, National Diabetes Information Clearinghouse.

A surgical procedure to take a healthy whole or partial pancreas from a donor and place it into a person with diabetes. 